\title{
Summer heatwaves promote blooms of harmful cyanobacteria
}

\author{
KLAUS D. JÖHNK ${ }^{*, 1,2}$, JEF HUISMAN ${ }^{*, 2}$, JONATHAN SHARPLES $\dagger$, BEN SOMMEIJER $\ddagger$, \\ PETRA M. VISSER* and JASPER M. STROOM \\ *Aquatic Microbiology, Institute for Biodiversity and Ecosystem Dynamics, University of Amsterdam, Nieuwe Achtergracht 127, \\ 1018 WS Amsterdam, The Netherlands, †Proudman Oceanographic Laboratory, University of Liverpool, 6 Brownlow Street, \\ Liverpool, L3 5DA, UK, †Center for Mathematics and Computer Science, Postbus 94079, 1090 GB Amsterdam, The Netherlands, \\ §Water Board Rijnland, PO Box 156, 2300 AD Leiden, The Netherlands
}

\begin{abstract}
Dense surface blooms of toxic cyanobacteria in eutrophic lakes may lead to mass mortalities of fish and birds, and provide a serious health threat for cattle, pets, and humans. It has been argued that global warming may increase the incidence of harmful algal blooms. Here, we report on a lake experiment where intermittent artificial mixing failed to control blooms of the harmful cyanobacterium Microcystis during the summer of 2003, one of the hottest summers ever recorded in Europe. To understand this failure, we develop a coupled biological-physical model investigating how competition for light between buoyant cyanobacteria, diatoms, and green algae in eutrophic lakes is affected by the meteorological conditions of this extreme summer heatwave. The model consists of a phytoplankton competition model coupled to a one-dimensional hydrodynamic model, driven by meteorological data. The model predicts that high temperatures favour cyanobacteria directly, through increased growth rates. Moreover, high temperatures also increase the stability of the water column, thereby reducing vertical turbulent mixing, which shifts the competitive balance in favour of buoyant cyanobacteria. Through these direct and indirect temperature effects, in combination with reduced wind speed and reduced cloudiness, summer heatwaves boost the development of harmful cyanobacterial blooms. These findings warn that climate change is likely to yield an increased threat of harmful cyanobacteria in eutrophic freshwater ecosystems.
\end{abstract}

Keywords: buoyant cyanobacteria, climate change, competition model, harmful algal blooms, heatwave, mixing, sinking phytoplankton, turbulence

Received 6 January 2006; revised version received 8 June 2007 and accepted 20 August 2007

\section{Introduction}

The summer of 2003 was probably the hottest summer in Europe of the past 500 years (Levinson \& Waple, 2004; Luterbacher et al., 2004). Temperature extremes were locally $5{ }^{\circ} \mathrm{C}$ higher than on average (Beniston, 2004). Climate models indicate that the summer heat-

Correspondence: Jef Huisman, Aquatic Microbiology, Institute for Biodiversity and Ecosystem Dynamics, University of Amsterdam, Nieuwe Achtergracht 127, 1018 WS Amsterdam, the Netherlands, tel. +31 20 5257085, fax +31 20 5257064,

e-mail: jef.huisman@science.uva.nl

${ }^{1}$ Present address: Leibniz-Institute of Freshwater Ecology and Inland Fisheries, Alte Fischerhütte 2, 16775 Neuglobsow, Germany.

${ }^{2} \mathrm{KDJ}$ and JH contributed equally to this work.

(C) 2008 The Authors

Journal compilation (C) 2008 Blackwell Publishing Ltd wave of 2003 might offer a glimpse of summers to be expected in Europe in the later part of this century, as a result of global warming (Beniston, 2004; Schär et al., 2004; Stott et al., 2004). During this hot summer, we ran a large-scale lake experiment to control surface blooms of the harmful cyanobacterium Microcystis.

Microcystis is a cosmopolitan cyanobacterium of eutrophic freshwaters (Reynolds et al., 1981; Zohary et al., 1996; Chen et al., 2003; Verspagen et al., 2006). Cells of Microcystis and several other cyanobacteria contain gas vesicles (Walsby, 1994), providing them with buoyancy. These buoyant cyanobacteria float upwards during weak vertical mixing, and can form dense blooms at the water surface (Zohary \& Robarts, 1990; Visser et al., 1996a). Moreover, Microcystis can produce microcystins, a family of toxins damaging the liver of birds and 
mammals, including humans. Hence, Microcystis blooms provide a serious threat for water quality (Chorus \& Bartram, 1999; Codd et al., 1999; Carmichael, 2001; Huisman et al., 2005). Previous studies have indicated that warm summers with little vertical mixing provide ideal conditions for surface blooms of harmful cyanobacteria (Reynolds, 1997; Ibelings et al., 2003; Robson \& Hamilton, 2003; Mooij et al., 2005). However, the lack of large-scale lake experiments and detailed mechanistic models has thus far limited rigorous predictions on the impact of weather conditions on cyanobacterial blooms.

Changes in vertical mixing may shift the competitive balance between buoyant cyanobacteria and sinking phytoplankton species (Walsby et al., 1997; Huisman et al., 2004). In this paper, we report on Lake Nieuwe Meer, a hypertrophic lake in the Netherlands, where artificial mixing successfully controls Microcystis blooms since 1993 (Visser et al., 1996a; Huisman et al., 2004). The entire lake is vertically mixed throughout summer by air bubbling. Artificial mixing led to major changes in phytoplankton species composition. Surface blooms of Microcystis dominating the lake before 1993 were replaced by a mixture of green algae and diatoms. Artificial mixing of Lake Nieuwe Meer is accompanied by an extensive monitoring program. Phytoplankton and nutrients are sampled frequently. Temperature loggers are moored in the lake to obtain online temperature records. A microstructure profiler is employed to monitor vertical mixing (Sharples et al., 2001; Huisman et al., 2004). We complemented the monitoring program by a model study of competition between buoyant cyanobacteria and sinking phytoplankton species. We coupled this phytoplankton competition model (Huisman et al., 1999a, 2004, 2006; Klausmeier \& Litchman, 2001) to a one-dimensional hydrodynamic model (Rodi, 1993; Mohammadi \& Pironneau, 1994; Jöhnk \& Umlauf, 2001; Hutter \& Jöhnk, 2004). The coupled biological-physical model is driven by meteorological fields such as irradiance, wind speed, and air temperature.

During the summer of 2003, we aimed to test a new mixing regime in Lake Nieuwe Meer. We implemented a scheme in which artificial mixing was switched on and off with a 1- or 2-week periodicity, to reduce the energy costs of artificial mixing without inducing surface blooms of harmful cyanobacteria. However, when we launched this research program, we were not aware that the summer of 2003 would become the hottest summer ever recorded in Europe. In August, at the peak of the summer heatwave, there were almost instant outbursts of Microcystis as soon as artificial mixing was switched off. In this paper, we report on the failure of intermittent mixing to suppress Microcystis blooms in
Lake Nieuwe Meer. We take advantage of our coupled biological-physical model to unravel which mechanisms promoted the development of surface blooms of these harmful cyanobacteria during the summer heatwave of 2003.

\section{Lake experiment}

Lake Nieuwe Meer is a recreational lake in the city of Amsterdam, with a surface area of $1.3 \mathrm{~km}^{2}$, a mean depth of $18 \mathrm{~m}$, and a maximum depth of $30 \mathrm{~m}$. The lake is connected to the canals of Amsterdam at one side and to a canal leading through the agricultural areas of the Haarlemmermeer Polder on the other side. The lake has very high nutrient concentrations (Table 1). Mean summer concentrations of total nitrogen in the epilimnion were up to $3800 \mu \mathrm{g} \mathrm{N} \mathrm{L}^{-1}$ in the late $1980 \mathrm{~s}$, and gradually declined to $2400 \mathrm{~g} \mathrm{~N} \mathrm{~L}^{-1}$ in 2006. Summer concentrations of total phosphorus amounted to $450 \mu \mathrm{g} \mathrm{PL}^{-1}$ in the late 1980s, and gradually declined to $260 \mu \mathrm{g} \mathrm{P} \mathrm{L}^{-1}$ in 2006. Dissolved inorganic nitrogen and soluble reactive phosphorus were never depleted to limiting values (Table 1; compare with Sas, 1989; Wetzel, 2001). Summer concentrations of silica usually ranged from 700 to $3000 \mu \mathrm{g} \mathrm{Si} \mathrm{L}^{-1}$, with a lower concentration of $100 \mu \mathrm{g} \mathrm{Si} \mathrm{L}^{-1}$ in August 1984. Accordingly, Lake Nieuwe Meer can be classified as a hypertrophic lake, where nutrient limitation of phytoplankton growth is negligible.

Dense surface blooms of the buoyant cyanobacterium Microcystis aeruginosa dominated the lake during summer for many years. In 1993, Water Board Rijnland installed a system of seven perforated air tubes just above the lake sediment to start artificial mixing of the lake by means of air bubbling. Artificial mixing led to major changes in phytoplankton species composition (Visser et al., 1996a; Huisman et al., 2004). Microcystis was replaced by a mixture of diatoms and large green

Table 1 Summer nutrient concentrations (in $\mu \mathrm{g} \mathrm{L}^{-1}$ ) in Lake Nieuwe Meer, measured monthly at $0.5 \mathrm{~m}$ depth in MayAugust

\begin{tabular}{lcccl}
\hline Nutrient & Mean & SD & Minimum & Maximum \\
\hline Total nitrogen & 3595 & 920 & 1800 & 6450 \\
$\begin{array}{l}\text { Dissolved inorganic } \\
\quad 2255\end{array}$ & 762 & 380 & 4100 \\
$\quad$ nitrogen & & & & \\
$\begin{array}{l}\text { Total phosphorus } \\
\text { Soluble reactive }\end{array}$ & 406 & 130 & 200 & 740 \\
$\quad$ phosphorus & 343 & 109 & 130 & 610 \\
Silicate & 1532 & 1268 & 100 & 4000 \\
\hline
\end{tabular}

Data show the mean, SD, minimum concentration and maximum concentration measured over the years 1980-2006. 
algae. The diatoms that became dominant by artificial mixing of Lake Nieuwe Meer consisted mainly of Cyclotella and Stephanodiscus species. The green algae that flourished with artificial mixing were dominated by Scenedesmus species, with smaller amounts of Monoraphidium, Kirchneriella, and Dictyosphaerium. Also, small flagellates (mainly Cryptomonas spp.) have become more abundant after artificial mixing was installed in the lake.

\section{Mixing experiment}

Artificial mixing of an entire lake requires quite some energy, and is, therefore, rather expensive. To reduce the costs, we therefore proposed an intermittent mixing regime, in which artificial mixing was alternately switched on and off for periods of 14 days during the summer of 2003. Artificial mixing of the lake was always off in winter. Artificial mixing was switched on at the end of April 2003. The intermittent mixing regime started on June 17, when artificial mixing was switched off for 2 weeks. This period was followed by only 1 week of artificial mixing (July 2-9), due to a failure in the air bubbling system. After this, the mixing was switched off for a period of 2 weeks (July 10-24), and subsequently switched on again for 2 weeks (July 25August 7). The next mixing-off period, in the second week of August, was in phase with the peak of the extreme heatwave across Europe. Within a few days, Microcystis rapidly increased. Although Microcystis concentrations were still far below those experienced during years without artificial mixing, the Water Board decided to switch mixing on permanently from August 14 onwards, thus suppressing the unexpected Microcystis bloom. The measurements ended on August 26.

\section{Temperature structure}

The temperature structure of the lake was monitored using a permanently moored vertical array of six temperature loggers (8-bit Minilog; VEMCO, Shad Bay, Nova Scotia, Canada), placed equidistantly from the water surface to $20 \mathrm{~m}$ deep with a spacing of $4 \mathrm{~m}$. The vertical array was mounted to a buoy near the middle of the lake. The temperature loggers recorded the temperature every $5 \mathrm{~min}$ over a period of 3 months, including the full experimental period.

\section{Turbulence structure}

The vertical turbulence structure can be derived from detailed profiles of the temperature microstructure (Imberger \& Ivey, 1991; Kocsis et al., 1999; Sharples et al., 2001). We employed a Self-Contained Autonomous
MicroProfiler (SCAMP; Precision Measurement Engineering Inc., Carlsbad, CA, USA) to measure highresolution profiles of temperature, pressure (depth), irradiance, chlorophyll fluorescence and conductivity (Stevens et al., 1999). The free-falling SCAMP was calibrated to sink downwards at a constant velocity of $\sim 10 \mathrm{~cm} \mathrm{~s}^{-1}$, collecting data at a frequency of $100 \mathrm{~Hz}$. This yields a vertical resolution of $\sim 1 \mathrm{~mm}$. SCAMP profiles were run at three sampling stations in the lake, on 16 sampling days spread over the experimental season. At each sampling station, we took 10 consecutive SCAMP profiles within $\sim 80 \mathrm{~min}$ to capture the variable nature of turbulent mixing. Turbulent dissipation rates and vertical turbulent diffusivities were calculated from the high-resolution temperature profiles according to Sharples et al. (2001).

\section{Phytoplankton development}

Water samples were taken from $1 \mathrm{~m}$ and $8 \mathrm{~m}$ depth at three sampling stations in the lake, on 17 days spread over the experimental season. The samples were fixed with Lugol's Iodine. Phytoplankton cells were counted microscopically using a Sedgewick-Rafter counting chamber and identified to the species level. Population abundances of the phytoplankton species, including colonial species like Microcystis, were expressed as number of cells per unit volume.

\section{Model study}

Complementary to the lake experiment, we developed a model to predict changes in temperature structure, turbulence structure, and phytoplankton population dynamics. The model consists of a one-dimensional hydrodynamic model coupled to a one-dimensional phytoplankton competition model. This coupled biological-physical model is forced by meteorological conditions, thus enabling model studies of different climate scenarios.

\section{Hydrodynamic model}

Simulations of temperature and turbulent diffusivity are based on a one-dimensional $k-\varepsilon$ turbulence model (Rodi, 1993; Mohammadi \& Pironneau, 1994; Jöhnk \& Umlauf, 2001; Hutter \& Jöhnk, 2004). Because Lake Nieuwe Meer is a relatively small lake, the Coriolis effect is insignificant and pressure gradients generated by internal seiching can be neglected. The turbulence model is based on a system of five partial differential equations, describing the dynamics of momentum, heat, turbulent kinetic energy, and turbulent dissipation rate, respectively. The depth of the lake is indicated by the 
variable $z$, where $z$ runs from 0 at the surface to a maximum depth $z_{m}$ at the bottom of the lake. The bathymetry of the lake is implicitly taken into account via the area-depth relation, $A(z)$.

Horizontal momentum related to the horizontal velocity vector, $\mathbf{u}$, is driven by wind stress at the surface, and vertically distributed by diffusion. The change in horizontal momentum can be described by a system of two partial differential equations (for momentum in the $x$ and $y$ direction, respectively)

$$
\frac{\partial \mathbf{u}}{\partial t}=\frac{\partial}{\partial z}\left(\left(D_{m}+D_{z}\right) \frac{\partial \mathbf{u}}{\partial z}\right)+c_{b} \mathbf{u}|\mathbf{u}| \frac{1}{A} \frac{\partial A}{\partial z},
$$

where $D_{m}$ is the molecular diffusivity of momentum for water and $D_{z}$ is the vertical turbulent diffusivity which is space- and time-dependent. The second term on the right-hand side describes the loss of momentum at each depth induced by the lake's boundaries. This boundary stress term is formulated as a sliding law with a drag coefficient $c_{b}$, chosen according to the lake's settings. The two boundary conditions for the momentum equation are the continuity of shear stress at the surface generated by wind stress, with a velocity-dependent drag coefficient, and vanishing shear stress at the deepest point of the lake (Hutter, 1993).

Heat is produced by the absorption of short-wave radiation (400-3000 $\mathrm{nm}), E(z, t)$, and vertically distributed by diffusion. Accordingly, dynamic changes in temperature, $T$, can be described as

$$
\frac{\partial T}{\partial t}=\frac{1}{A} \frac{\partial}{\partial z}\left(A\left(D_{h}+\frac{D_{z}}{\sigma_{h}}\right) \frac{\partial T}{\partial z}\right)-\frac{1}{\rho(T) c(T)} \frac{\partial E}{\partial z}
$$

where $D_{h}$ is the molecular diffusivity of heat in water, and $D_{z} / \sigma_{h}$ is the turbulent diffusivity of heat expressed as the turbulent diffusivity of momentum divided by the Prandtl-number for heat, $\sigma_{h}$. The Prandtl-number is parameterized as a function of turbulent kinetic energy, turbulent dissipation rate, and temperature gradient. The bathymetry of the lake is implicitly incorporated via the area-depth relation, $A(z)$, in such a way that heat is conserved and radiation reaching the lake bottom is absorbed by the sediment. We neglect heat exchange between the water column and sediments, which is a common assumption for deep lakes (unless the water is heated from below by geothermal activity; e.g. Imboden \& Wüest, 1995). The second term on the right-hand side describes the absorption of short-wave radiation, where $\rho(T)$ is the density of water and $c(T)$ is the specific heat of water, with both being functions of temperature (Chen \& Millero, 1986). Short-wave radiation in the water column depends on the incident radiation at the water surface, and decreases exponentially with depth according to Lambert-Beer's law. The two boundary conditions for the heat equation are the continuity of heat flux at the surface, driven by meteorological conditions, and a vanishing heat flux at the deepest point of the lake (Henderson-Sellers, 1984; Hutter \& Jöhnk, 2004).

The dynamical distributions of turbulent kinetic energy, $k$, and turbulent dissipation rate, $\varepsilon$, are described by the two equations (Jones \& Launder, 1972; Rodi, 1993; Mohammadi \& Pironneau, 1994; Hutter \& Jöhnk, 2004):

$$
\begin{aligned}
& \frac{\partial k}{\partial t}=\frac{\partial}{\partial z}\left(\left(D_{m}+\frac{D_{z}}{\sigma_{k}}\right) \frac{\partial k}{\partial z}\right)+P+G-\varepsilon \\
& \frac{\partial \varepsilon}{\partial t}=\frac{\partial}{\partial z}\left(\left(D_{m}+\frac{D_{z}}{\sigma_{\varepsilon}}\right) \frac{\partial \varepsilon}{\partial z}\right)+\left(c_{1 \varepsilon} P+c_{3 \varepsilon} G-c_{2 \varepsilon} \varepsilon\right) \frac{\varepsilon}{k},
\end{aligned}
$$

where $P$ and $G$ describe the production and loss of turbulent kinetic energy induced by shearing of the flow and buoyancy, respectively. Furthermore, $\sigma_{k}$ and $\sigma_{\varepsilon}$ are the Prandtl-numbers for turbulent kinetic energy and turbulent dissipation rate, both assumed to be constant, and $c_{1 \varepsilon}, c_{2 \varepsilon}$, and $c_{3 \varepsilon}$ are constants. Production and loss of turbulent kinetic energy are functions of the velocity gradient and the temperature gradient, respectively,

$$
P=D_{z}\left|\frac{\partial \mathbf{u}}{\partial z}\right|^{2}, \quad G=\theta(T) g \frac{D_{z}}{\sigma_{h}} \frac{\partial T}{\partial z}
$$

where $\theta(T)$ is the temperature-dependent thermal expansion coefficient of water, and $g=9.81 \mathrm{~m} \mathrm{~s}^{-2}$ is the Earth's gravitational acceleration. At the boundaries, the turbulent fields are determined by heat and momentum fluxes at the interface (Wilcox, 1993), extended for buoyant fluids (Svensson, 1978). The constants and the Prandtlnumbers of the $k-\varepsilon$ turbulence model take their usual values (Launder \& Spalding, 1974; Rodi, 1993; Mohammadi \& Pironneau, 1994; Hutter \& Jöhnk, 2004).

Finally, the vertical profile of turbulent diffusivity when artificial mixing is switched off is calculated from the relation

$$
D_{z}=c_{\mu} \frac{k^{2}}{\varepsilon},
$$

where the constant of proportionality, $c_{\mu}$, takes the usual value of 0.09 (Rodi, 1993; Mohammadi \& Pironneau, 1994; Hutter \& Jöhnk, 2004). When artificial mixing is switched on, the turbulent diffusivity is much higher. Based on SCAMP measurements in 2003, we estimated that artificial mixing contributed a background turbulent diffusivity of $\sim 1.6 \times 10^{-3} \mathrm{~m}^{2} \mathrm{~s}^{-1}$. This value is added to Eqn (5) when artificial mixing is on. 
The full set of equations was integrated in time using an implicit method on an equidistant space-time grid with a spatial resolution of $0.1 \mathrm{~m}$ and a time resolution of $4 \mathrm{~min}$. Initial values of the hydrodynamic model were a homogeneous temperature of $4{ }^{\circ} \mathrm{C}$ and zero values for all other profiles on 1 January. For each simulation, the hydrodynamic model was run over 3 years of meteorological forcing to equilibrate the hydrodynamics with the prevailing climate conditions. Only the last year of each run was coupled to the phytoplankton competition model.

\section{Phytoplankton model}

Simulations of the phytoplankton are based on a onedimensional phytoplankton competition model developed by Huisman and co-workers (Huisman et al., 1999a, b, 2004, 2006). We consider a vertical water column with a total number of $n$ different phytoplankton species. Because Lake Nieuwe Meer is a hypertrophic lake with very high nutrient concentrations (Table 1), the model assumes that nutrient limitation of the phytoplankton does not play a role. The population dynamics of the phytoplankton species are driven by light availability, temperature, and mixing processes.

More precisely, let $N_{i}(z, t)$ denote the population density of phytoplankton species $i$ at depth $z$ and time $t$, let $I(z, t)$ denote the local light intensity in the PAR range $(400-700 \mathrm{~nm})$, and let $T(z, t)$ denote the local temperature (in ${ }^{\circ} \mathrm{C}$ ). The population dynamics of the phytoplankton species are described by a system of reaction-advection-diffusion equations (Huisman et al., 2004, 2006):

$$
\begin{aligned}
\frac{\partial N_{i}}{\partial t}= & \mu_{i}(I, T) N_{i}-m_{i}(T) N_{i}+\frac{\partial}{\partial z}\left(v_{i}(T) N_{i}\right) \\
& +\frac{\partial}{\partial z}\left(D_{z} \frac{\partial N_{i}}{\partial z}\right) \quad i=1, \ldots, n .
\end{aligned}
$$

Here, $\mu_{i}(I, T)$ is the specific growth rate of species $i$ as a function of light intensity and temperature. The term $m_{i}(T)$ is the specific loss rate of species $i$ as a function of temperature, and includes losses due to natural mortality, zooplankton grazing, and virus attack. Furthermore, $v_{i}(T)$ is the vertical velocity of species $i$ (with $v_{i}>0$ for buoyant species, and $v_{i}<0$ for sinking species), which depends on the viscosity of the water and, thereby, on temperature. Finally, $D_{z}$ is the vertical turbulent diffusivity, which is space- and time-dependent. Zeroflux boundary conditions at the top and the bottom of the water column assure that the phytoplankton species neither enter nor leave the water column.
The underwater light conditions may change. For instance, the water column will become more turbid with increasing phytoplankton population densities. More specifically, according to Lambert-Beer's law, the underwater light gradient can be described as (Huisman \& Sommeijer, 2002; Huisman et al., 2004):

$I(z, t)=I_{\text {in }}(t)(1-r) \exp \left(-\int_{0}^{z}\left[\sum_{i=1}^{n} \kappa_{i} N_{i}(\sigma, t)\right] d \sigma-K_{b g} z\right)$,

where $I_{\text {in }}(t)$ is the incident light intensity (PAR) at the water surface, $r$ is a reflection coefficient to correct for reflection losses at the water surface, $\kappa_{i}$ is the specific light attenuation coefficient of phytoplankton species $i, K_{b g}$ is the background attenuation coefficient caused by all nonphytoplankton components in the water column, and $\sigma$ is an integration variable accounting for the nonuniform phytoplankton population density distributions.

The model assumes that the specific growth rate is an increasing saturating function of light intensity, as described by a simple Monod equation (Huisman et al., 1999a; Passarge et al., 2006):

$$
\mu_{i}(I, T)=\frac{\mu_{\max , i}(T) I}{\mu_{\max , i}(T) / \alpha_{i}+I},
$$

where $\mu_{\text {max }, i}(T)$ is the maximum specific growth rate of species $i$ at light-saturating conditions as a function of temperature, and $\alpha_{i}$ is the initial slope of the growth function under light-limited conditions. The slope $\alpha_{i}$ is mainly determined by temperature-independent processes of the light reaction of photosynthesis (like light absorption), whereas $\mu_{\text {max }, i}$ is mainly determined by the temperature-dependent processes of the dark reaction of photosynthesis (Raven \& Geider, 1988; Coles \& Jones, 2000). We, therefore, assume that $\mu_{\max , i}$ varies with temperature, while $\alpha_{i}$ is independent of temperature.

The temperature dependence of the maximum specific growth rate is described by an optimum curve, which increases with temperature according to an Arrhenius-type relationship, but decreases with temperature when the temperature optimum, $T_{\text {opt }, i}$, is exceeded. Our functional relationship is based on Robson \& Hamilton (2004), but reformulated to better describe the point of the temperature optimum:

$$
\begin{aligned}
\mu_{\max , i}(T)= & \mu_{\max , i}\left(T_{o p t, i}\right)\left[1+b_{i}\left(\left(R_{1 i}^{T-T_{o p t, i}}-1\right)\right.\right. \\
& \left.\left.-\frac{\ln \left(R_{1 i}\right)}{\ln \left(R_{2 i}\right)}\left(R_{2 i}^{T-T_{o p t, i}}-1\right)\right)\right]
\end{aligned}
$$

where $\mu_{\max , i}\left(T_{o p t, i}\right)$ is the maximum specific growth rate at the optimum temperature, and the parameters $R_{1 i}$, $R_{2 i}$, and $b_{i}$ describe the form of the optimum curve for 
species $i$. The curve fits well to existing data of the temperature dependence of maximum specific growth rates (Reynolds, 1997; Butterwick et al., 2005). We assume that the specific loss rate increases exponentially with temperature, as described by a simple $Q_{10}$ relationship (Robarts \& Zohary, 1987; Ryan, 1991):

$$
m_{i}(T)=m_{i}(20) Q_{i}^{(T-20) / 10},
$$

where $m_{i}(20)$ is the specific loss rate at $20^{\circ} \mathrm{C}$, and $Q_{i}$ describes the change in specific loss rate with a temperature change of $10^{\circ} \mathrm{C}$.

According to Stokes' Law, the vertical velocity of a nonmotile phytoplankter at low Reynolds numbers is inversely proportional to the dynamic viscosity of water (Smayda, 1970; Reynolds, 2006). Dynamic viscosity, in turn, varies with temperature (e.g. Hutter \& Jöhnk, 2004). Accordingly, we modelled the temperature dependence of the vertical velocity of the different phytoplankton species as

$$
v_{i}(T)=\frac{\eta(20)}{\eta(T)} v_{i}(20),
$$

where $\eta(T)$ is the dynamic viscosity as a function of temperature, and $\eta(20)$ and $v_{i}(20)$ are the dynamic viscosity and vertical velocity at a reference temperature of $20^{\circ} \mathrm{C}$. Because dynamic viscosity decreases with temperature, buoyant cyanobacteria will float upwards faster while sinking phytoplankton will sink faster with increasing temperature.

Numerical simulation of the phytoplankton competition model is computationally quite demanding, due to a nonlocal term in the model (i.e. the integral term in Eqn 7). A detailed presentation of our simulation techniques, with tests of the accuracy and numerical stability of the simulations, is presented in Huisman and Sommeijer (2002) and Pham Thi et al. (2005). The model was forced by the temperature field and turbulent diffusivity field predicted by the hydrodynamic model, and the incident light intensity (PAR, from 400 to $700 \mathrm{~nm}$ ) measured hourly at the weather station of Schiphol airport. Simulations of the population dynamics of the phytoplankton species during the summer season were initiated with homogeneous population density distributions of the phytoplankton on the first of May.

\section{Climate scenarios}

Hourly values of incident radiation, air temperature, relative humidity, wind speed, and cloudiness were provided by the Royal Netherlands Meteorological Institute (KNMI) from the weather station of Schiphol airport, which is only $\sim 5 \mathrm{~km}$ southwest of Lake Nieuwe Meer. These meteorological variables were used as input in the model simulations.
To investigate different climate scenarios, we chose 3 years characterized by contrasting summer temperatures, wind speeds, and cloud cover. Changes in cloud cover affect the incident radiation. This was described by a simple empirical relation (Jöhnk, 2005):

$$
I_{\text {in }}=\left(1-0.65 C^{2}\right) I_{\text {sol }} \text {, }
$$

where $C$ is cloud cover $(0<\mathrm{C}<1)$ and $I_{\text {sol }}$ is the solar radiation for a clear sky. According to long-term meteorological measurements of the Royal Netherlands Meteorological Institute (KNMI) in De Bilt, the Netherlands, summer air temperature increased significantly during the past century (Fig. 1a; slope $=0.011 \pm 0.003^{\circ} \mathrm{C} \mathrm{yr}^{-1}$, $P<0.0002)$. Summer values of wind speed and cloudiness showed no significant trend (Fig. $1 b$ and c). The selected years were 1956, 1991, and 2003 (Fig. 1). The summer of 1956 can be regarded as a cold summer, with high wind speeds and large cloudiness. In 1991, summer temperatures, wind speeds, and cloud cover had average values. The summer of 2003, which may reflect a glimpse of climate change to come (Beniston, 2004; Schär et al., 2004; Stott et al., 2004), was extremely hot with little cloud cover and low wind speeds.

\section{Model calibration}

During the years 1990 and 1991 artificial mixing was not yet applied to the lake. We used the meteorological data, temperature structure, and phytoplankton development monitored during these 2 years to calibrate the hydrodynamic model and the phytoplankton model.

\section{Hydrodynamic model}

Wind speed and the drag coefficient in the momentum equation (Eqn 1) were the only parameters that were tuned to calibrate the hydrodynamic model. All other model parameters took standard values for lakes typical of the temperate region (Table 2). Simulations yielded the best fit when the wind speed measured at Schiphol airport was scaled by a factor of 0.92 . That is, only a slight reduction of wind speed by $8 \%$ was required to calibrate the hydrodynamic model, most likely due to differences in fetch or terrain roughness between Schiphol airport and Lake Nieuwe Meer. The drag coefficient in the momentum equation was adjusted to fit the stratification behaviour of the lake. The seasonal development of the temperature stratification predicted by the calibrated model was in good agreement with the observed temperature stratification (Fig. 2a).

The incident radiation followed the ambient daynight cycle, based on hourly measurements at the 
(a)

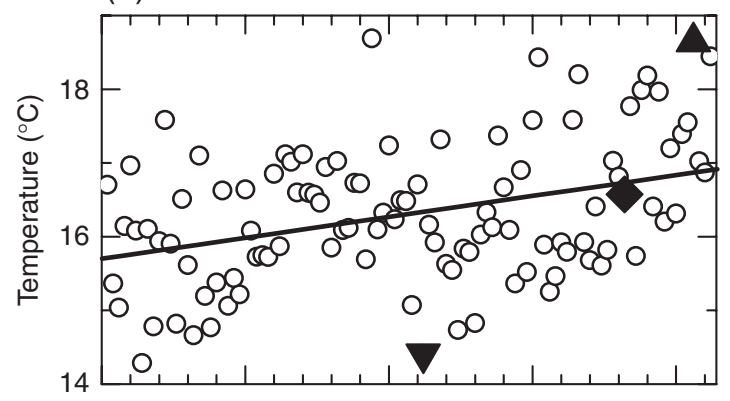

(b)

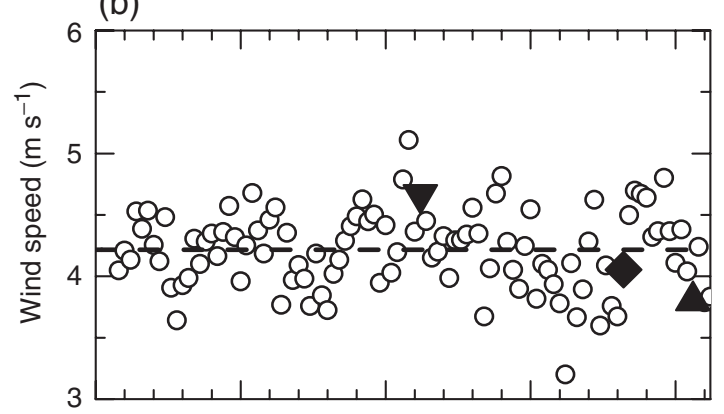

(c)

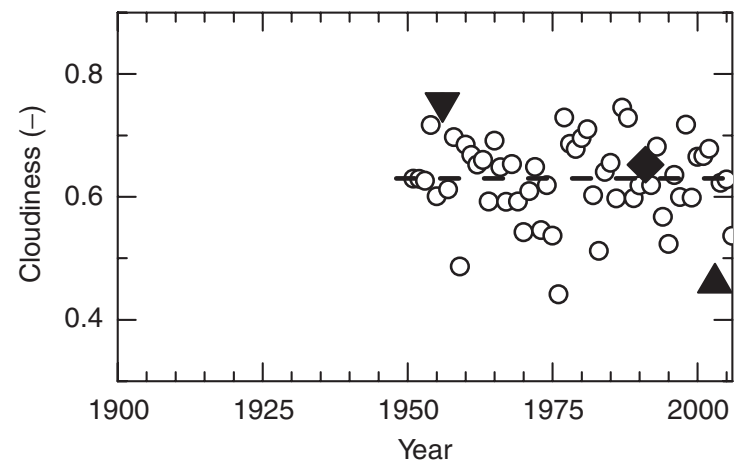

Fig. 1 Summer weather conditions measured at De Bilt, the Netherlands, during the past century. (a) Summer air temperature. (b) Summer wind speed. (c) Summer cloud cover. Open circles show the average values over the months June, July, and August of each year. Solid line in (a) shows the significant trend line for air temperature. Dashed lines in (b and c) show the longterm means for wind speed and cloud cover. Additional symbols represent selected years, a very cold summer (1956; inverted triangle), an average summer (1991; diamond), and a very hot summer (2003; triangle).

weather station of Schiphol airport. Incident light is partially reflected at the water surface. This process was accounted for by a mean reflectivity of $r=0.06$. The background attenuation coefficient for the underwater light field (Eqn 7) was calibrated, yielding a value of $K_{b g}=0.7 \mathrm{~m}^{-1}$. This is close to measured values of $K_{b g}=0.6 \mathrm{~m}^{-1}$ in Lake Nieuwe Meer (Huisman et al., 2004).

\section{Phytoplankton model}

We applied the model to study competition of the harmful cyanobacterium Microcystis against diatoms and green algae in Lake Nieuwe Meer. Parameter values and their sources are listed in Table 3.

The temperature dependence of the maximum specific growth rate, described by Eqn 9, was fitted to laboratory measurements of Microcystis (Reynolds, 1997). This yielded an excellent fit (Fig. 2b, blue line; $R^{2}=0.99$, $N=6$ ). The general shape of the temperature-dependent growth rate of the diatoms was fitted to laboratory measurements of the freshwater diatom Asterionella (Butterwick et al., 2005). Because Lake Nieuwe Meer also hosts several other diatom species (especially Stephanodiscus and Cyclotella spp.), we calibrated the height of this temperature response curve [i.e. the parameter $\left.\mu_{\max , i}\left(T_{o p t, i}\right)\right]$ against the seasonal phytoplankton data of 1990 and 1991. The model calibration yielded a very good correspondence with the laboratory data of Asterionella (Fig. 2b, compare red symbols and red line). The literature did not provide suitable data on the temperature-dependent growth rates of green algae representative for Lake Nieuwe Meer. Therefore, the temperature dependence of the green algae was fully calibrated against the seasonal phytoplankton data of 1990 and 1991. This yielded a quite plausible temperature response curve (Fig. 2b, green line). Comparison of the three temperature response curves shows that Microcystis has a lower maximum specific growth rate than the diatoms and green algae at temperatures below $23^{\circ} \mathrm{C}$. However, the specific growth rate of Microcystis shows a stronger increase with temperature and higher optimum temperature than the diatoms and green algae (Fig. 2b). This makes Microcystis a relatively weak competitor at low temperatures, but a strong competitor at high temperatures.

The specific loss rate of Microcystis, described by Eqn 10, was adopted from Robson \& Hamilton (2004). Grazing losses were probably low for Microcystis, due to its large colony size, toxin production, and mucilaginous envelope (DeMott, 1999; Rohrlack et al., 1999; Ghadouani et al., 2003), but might be more substantial for the diatoms and green algae. We lack detailed zooplankton counts for Lake Nieuwe Meer, however. Therefore, the specific loss rates of the diatoms and green algae were estimated by calibration of the model against the seasonal phytoplankton data of 1990 and 1991.

The flotation velocity of Microcystis was adopted from Huisman et al. (2004). The sinking velocities of the diatoms and green algae were estimated by model calibration, and the values thus obtained (Table 3) were of similar magnitude as the measured sinking velocities of diatoms and green algae isolated from Lake Nieuwe 
Table 2 Environmental parameters used in the model simulations

\begin{tabular}{|c|c|c|c|c|}
\hline Parameter & Description & Value & Units & Source \\
\hline \multicolumn{5}{|c|}{ Momentum and heat balance equations } \\
\hline$D_{m}$ & Molecular diffusivity of momentum & $10^{-6}$ & $\mathrm{~m}^{2} \mathrm{~s}^{-1}$ & Hutter \& Jöhnk (2004) \\
\hline$D_{h}$ & Molecular diffusivity of heat & $1.3 \times 10^{-7}$ & $\mathrm{~m}^{2} \mathrm{~s}^{-1}$ & Hutter \& Jöhnk (2004) \\
\hline$\rho$ & Density & $\rho(T)$ & $\mathrm{kg} \mathrm{m}^{-3}$ & Chen \& Millero (1986) \\
\hline$\theta$ & Coefficient of thermal expansion & $\theta(T)$ & $\mathrm{K}^{-1}$ & Chen \& Millero (1986) \\
\hline$c$ & Specific heat & $c(T)$ & $\mathrm{Jkg}^{-1} \mathrm{~K}^{-1}$ & Chen \& Millero (1986) \\
\hline $\mathrm{A}$ & Area-depth relation & $A(z)$ & $\mathrm{m}^{2}$ & Measured \\
\hline$c_{b}$ & Drag coefficient in momentum equation & 0.004 & - & Calibrated \\
\hline$U_{\text {scale }}$ & Scaling of wind velocity & 0.92 & - & Calibrated \\
\hline \multicolumn{5}{|c|}{ Turbulence equations } \\
\hline$c_{\mu}$ & Coefficient in eddy viscosity & 0.09 & - & Rodi (1993) \\
\hline$c_{1 \varepsilon}$ & $\begin{array}{l}\text { Coefficient in shear production of turbulent } \\
\text { dissipation }\end{array}$ & 1.44 & - & Rodi (1993) \\
\hline$c_{2 \varepsilon}$ & Coefficient in turbulent dissipation & 1.92 & - & Rodi (1993) \\
\hline$c_{3 \varepsilon}$ & $\begin{array}{l}\text { Coefficient in buoyancy production of turbulent } \\
\text { dissipation }\end{array}$ & 0.8 & - & Rodi (1993) \\
\hline$\sigma_{k}$ & Prandtl-number of turbulent kinetic energy & 1.0 & - & Rodi (1993) \\
\hline$\sigma_{\varepsilon}$ & Prandtl-number of turbulent dissipation & 1.3 & - & Rodi (1993) \\
\hline$\sigma_{h}$ & Prandtl-number of heat & $\sigma_{h}(k, \varepsilon, \mathrm{d} T / \mathrm{d} z)$ & - & Svensson (1978) \\
\hline \multicolumn{5}{|c|}{ Light gradient } \\
\hline$I_{\text {in }}$ & Incident light intensity & $I_{i n}(t)$ & $\mu \mathrm{mol} \mathrm{m}{ }^{-2} \mathrm{~s}^{-1}$ & Measured \\
\hline$r$ & Reflection coefficient & 0.06 & - & Calibrated \\
\hline$K_{b g}$ & Background attenuation coefficient & 0.70 & $\mathrm{~m}^{-1}$ & Calibrated \\
\hline \multicolumn{5}{|l|}{ Viscosity } \\
\hline$\eta$ & Dynamic viscosity & $\eta(T)$ & $\mathrm{kg} \mathrm{m}^{-1} \mathrm{~s}^{-1}$ & Hutter \& Jöhnk (2004) \\
\hline
\end{tabular}

Meer (Visser et al., 1996b). The temperature dependence of the dynamic viscosity of water was taken from the literature (Hutter \& Jöhnk, 2004). Because Microcystis can float upwards, whereas the diatoms and to a lesser extent also the green algae sink downwards, Microcystis may gain a competitive edge during periods with weak vertical mixing (Visser et al., 1996a; Huisman et al., 2004).

The population dynamics of the phytoplankton species predicted by the calibrated model were in good agreement with the observed population dynamics of Microcystis and the diatoms and green algae in Lake Nieuwe Meer (Fig. 2c and d). As predicted, the cell concentrations of Microcystis during August and September were two orders of magnitude higher than the cell concentrations of the diatoms and green algae when the lake was not artificially mixed. The full model, calibrated on the basis of the years 1990 and 1991, was used to predict the temperature structure, turbulence structure, and phytoplankton development in 2003.

\section{Results}

\section{Lake experiment}

The intermittent mixing regime imposed by artificial mixing (Fig. 3a) had a major impact on the turbulence structure, temperature structure, and phytoplankton development in 2003. Vertical turbulent diffusivity was, on average, $\sim 3$ orders of magnitude higher with artificial mixing than without artificial mixing (Fig. 3b). When artificial mixing was switched off, the lake stratified in $\sim 7$ days with a thermocline at $\sim 5 \mathrm{~m}$ depth (Fig. 3c). In mid-August, when air temperatures soared high at $\sim 35^{\circ} \mathrm{C}$, lake temperature reacted even faster and a strong temperature stratification built up within 2-4 days. The water temperature near the surface increased up to a maximum of $24^{\circ} \mathrm{C}$ in mid-August (Fig. 3d). Switching on the artificial mixing typically resulted in a temporary drop in the near-surface temperature, due to mixing of warm surface water with colder water from below. The stratification generally disappeared within a few days.

During artificial mixing, the Microcystis population was efficiently suppressed (Fig. 3e). However, when artificial mixing was switched off for the second time, in mid-July, the Microcystis population increased. The increase of Microcystis was even stronger during the next period without artificial mixing. In mid-August, at the peak of the summer heatwave, an almost instant outburst of Microcystis appeared as soon as artificial mixing was switched off (Fig. 3e). Subsequently, the Water Board responsible for the water quality of the 
(a)
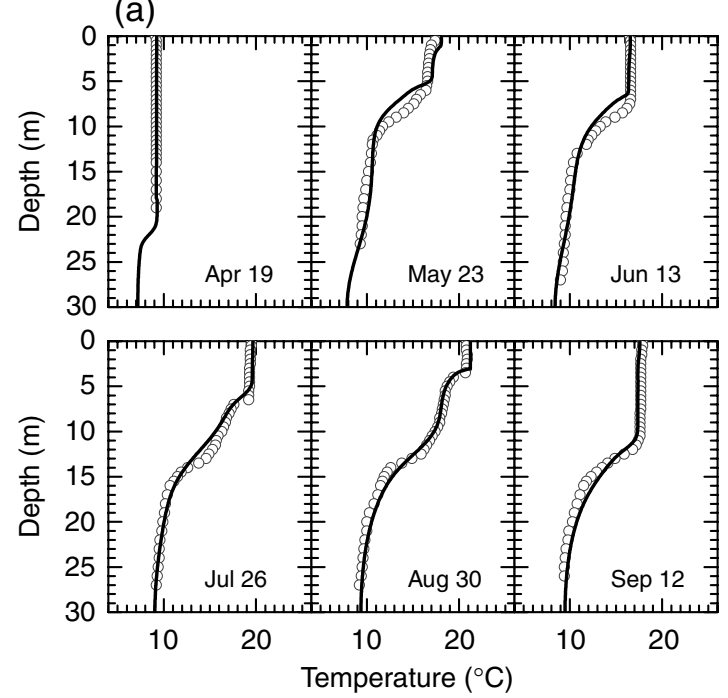

(b)

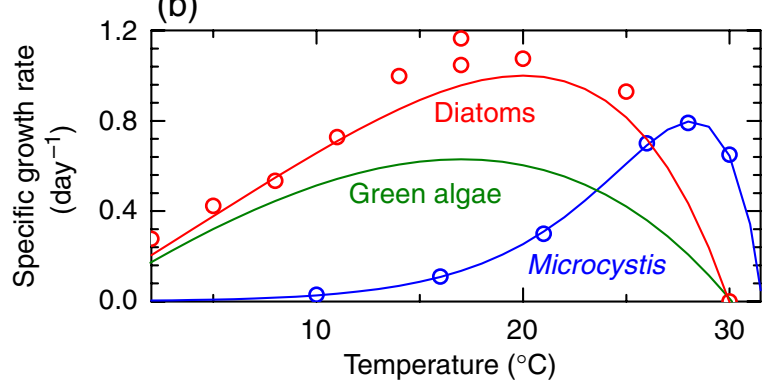

(c)

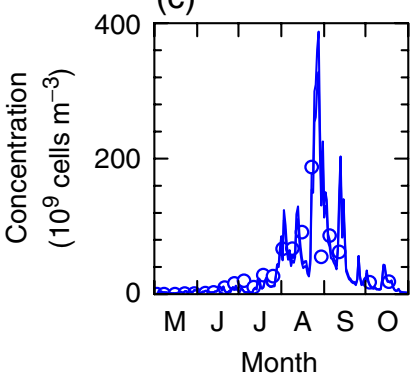

(d)

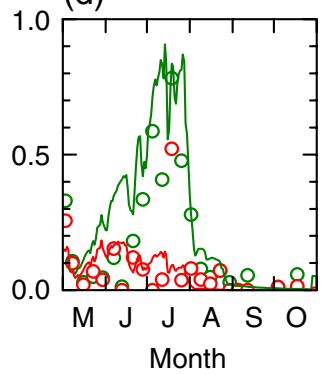

Fig. 2 Model calibration. (a) Temperature profiles in Lake Nieuwe Meer during the summer of 1990. (b) Effect of temperature on the maximum specific growth rates of Microcystis (blue line), diatoms (red line), and green algae (green line) representative for Lake Nieuwe Meer. Data points of Microcystis are from Reynolds (1997); data points of the diatoms are from laboratory measurements of Asterionella (Butterwick et al., 2005). The temperature dependence of the green algae was estimated by model calibration against the seasonal phytoplankton data of 1990 and 1991. (c) Population dynamics of Microcystis, diatoms, and green algae near the water surface $(0-1 \mathrm{~m})$ of Lake Nieuwe Meer during the summer of 1990. Symbols represent measured data, solid lines represent model predictions.

lake decided to switch artificial mixing on permanently, thus suppressing the harmful cyanobacterium Microcystis during the rest of the season.
Diatoms and green algae showed a weaker response to the intermittent mixing regime. The green algae showed little variability (Fig. 3f, green symbols and line). The diatoms increased slightly during the first and second mixing-off period (Fig. $3 f$, red symbols and line), when the water temperature was near their optimum temperature (Fig. 2b). During the third mixing-off period, in mid-August, the diatom concentration dropped, most likely due to high water temperatures exceeding their temperature optimum combined with rapid sedimentation caused by reduced turbulent mixing. As a result, during the third mixing-off period, Microcystis reached 50 times higher cell concentrations at the surface than the diatoms and green algae.

During the mixing-off periods, Microcystis reached 30-50 times higher concentrations near the water surface than at $8 \mathrm{~m}$ depth. This indicates that many Microcystis cells floated upwards when mixing was off. For comparison, diatoms and green algae reached at most $\sim 4$ times higher concentrations near the water surface than at $8 \mathrm{~m}$ depth during mixing-off periods. When artificial mixing was switched on, the phytoplankton concentrations were always very similar at 1 and $8 \mathrm{~m}$ depth, indicating that artificial mixing resulted in effective vertical homogenization of Microcystis and all other phytoplankton populations.

\section{Model simulation of the lake experiment}

Model predictions of the hydrodynamic model were generally in very good agreement with the measured turbulence structure and temperature structure of 2003. Both long-term trends and short-term fluctuations were captured by the model. An example is shown in Fig. 3d, which illustrates the excellent match between the predicted and measured temperature near the water surface. The model predictions were also largely consistent with the observed phytoplankton population dynamics. During the first mixing-off period, in June, the model predicted a small Microcystis peak, which was not visible in the data (Fig. 3e). This might be due to horizontal patchiness in the distribution of buoyant cyanobacteria. The increase of Microcystis in the second mixing-off period in July, the main outburst of Microcystis in the third mixing-off period in mid-August, and the rapid decline of Microcystis when mixing was switched on, were all captured by the model predictions (Fig. 3e). Diatoms and green algae could also be simulated fairly well (Fig. 3f).

Which species traits enabled the ecological success of Microcystis during the summer heatwave of 2003? To address this question, we explored model simulations in which we gave our modelled Microcystis different traits. For instance, we shifted the temperature 
Table 3 Species parameters used in the model simulations

\begin{tabular}{|c|c|c|c|c|c|}
\hline Parameter & Description & Microcystis & Diatoms & Green algae & Units \\
\hline$\mu_{\max }\left(T_{o p t}\right)$ & $\begin{array}{l}\text { Maximum specific growth rate at optimum } \\
\text { temperature }\end{array}$ & $0.80^{(1)}$ & $1.00^{*(2)}$ & $0.63^{*}$ & day $^{-1}$ \\
\hline$\alpha$ & Initial slope of light-dependent growth & $0.01^{*}$ & $0.035^{*}$ & $0.035^{*}$ & $\begin{array}{l}\text { day }^{-1} \\
\qquad\left(\mu \mathrm{mol} \mathrm{m}{ }^{-2} \mathrm{~s}^{-1}\right)^{-1}\end{array}$ \\
\hline$T_{o p t}$ & Optimum temperature & $28.2^{(1)}$ & $20.0^{(2)}$ & $17.0^{*}$ & ${ }^{\circ} \mathrm{C}$ \\
\hline$b$ & Coefficient in optimum curve & $5.77^{(1)}$ & $4.68^{(2)}$ & $18.61^{*}$ & - \\
\hline$R_{1}$ & Coefficient in optimum curve & $1.30^{(1)}$ & $1.02^{(2)}$ & $1.02^{*}$ & - \\
\hline$R_{2}$ & Coefficient in optimum curve & $1.37^{(1)}$ & $1.15^{(2)}$ & $1.04^{*}$ & - \\
\hline$m(20)$ & Specific loss rate at $20^{\circ} \mathrm{C}$ & $0.08^{(3)}$ & $0.08^{*}$ & $0.06^{*}$ & day $^{-1}$ \\
\hline$Q$ & Temperature dependence of specific loss rate & $2.16^{(3)}$ & $1.63^{(3)}$ & $1.63^{*}$ & - \\
\hline$\kappa$ & Specific light attenuation coefficient & $3.4^{(4)}$ & $70^{(4)}$ & $70^{*}$ & $\mu \mathrm{m}^{2}$ cell $^{-1}$ \\
\hline$v$ & Sinking or flotation velocity & $0.500^{(4)}$ & $-0.06^{*}$ & $-0.04^{*}$ & $\mathrm{mh}^{-1}$ \\
\hline$N(0)$ & Initial population density & $5 \times 10^{8^{*}}$ & $0.5 \times 10^{8^{*}}$ & $0.5 \times 10^{8 *}$ & cells $\mathrm{m}^{-3}$ \\
\hline
\end{tabular}

*Parameter values obtained by model calibration.

Sources of the parameter estimates: (1) Reynolds (1997); (2) Butterwick et al. (2005); (3) Robson \& Hamilton (2004); (4) Huisman et al. (2004).

optimum of Microcystis downwards, from 28 to $20^{\circ} \mathrm{C}$, to match the temperature optimum of the diatoms while keeping all other Microcystis parameters the same. In these model simulations, the Microcystis population peaked much more strongly during the second mixing-off period in mid-July when temperatures were close to $20^{\circ} \mathrm{C}$, while the Microcystis population remained smaller during the third mixing-off period in mid-August because the higher temperatures inhibited its growth rate. We also investigated model simulations in which the buoyancy of Microcystis was removed. Without its buoyancy, Microcystis could not float to the surface when mixing was off, and thereby lost its competitive edge in comparison with diatoms and green algae. Hence, Microcystis quickly disappeared. In total, these simulations show that the ecological success of Microcystis during summer heatwaves can be attributed to its positive buoyancy in combination with its high-temperature optimum compared with other phytoplankton. These are highly advantageous traits during stratified and warm conditions.

\section{Model study of climate scenarios}

To investigate in further detail how weather conditions during the summer season (May-October) would affect the development of harmful cyanobacteria, we simulated the full model for three different summers: the cold summer of 1956, the average summer of 1991, and the exceptionally hot summer of 2003. In these model simulations, artificial mixing was switched off. That is, the hydrodynamics and phytoplankton population dynamics in the lake were solely driven by meteorological forcing.

The model predictions showed that in cold summers, like 1956, the temperature stratification in the lake was relatively weak and diatoms and green algae reached their highest concentrations at the end of June and early July (Fig. 4a). From mid-July onwards, Microcystis formed surface blooms, with cell concentrations reaching $\sim 0.2 \times 10^{12}$ cells m $^{-3}$ in August and September. For 'average' meteorological conditions, as in the summer of 1991, the model predictions yielded a rather similar picture. Diatoms and green algae dominated in June and early July, while a Microcystis bloom developed in late summer, when lake surface temperatures and stability conditions were in favour of buoyant cyanobacteria (Fig. 4b). Storms and surface cooling associated with strong mixing suppressed the Microcystis bloom in September. During the exceptionally hot summer of 2003, the model predicted the development of a warm surface layer with little vertical mixing from early June onwards (Fig. 4c). This triggered high specific growth rates of Microcystis floating towards the surface, which resulted in dense Microcystis blooms with cell concentrations exceeding $1.2 \times 10^{12}$ cells $\mathrm{m}^{-3}$ at the height of the summer heatwave in mid-August (Fig. 4c). Diatoms and green algae, in contrast, suffered from the early development of a stable stratification. Their sedimentation losses exceeded their growth rates, keeping their cell concentrations at very low values from early summer onwards.

In all 3 years, the model predicted rather spiky patterns for the surface concentrations of Microcystis (Fig. 4, third row, solid lines). These spikes represent 
(a)

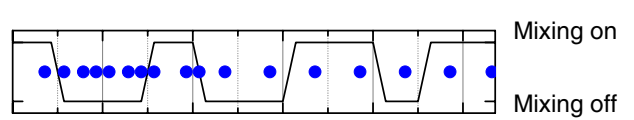

(b)

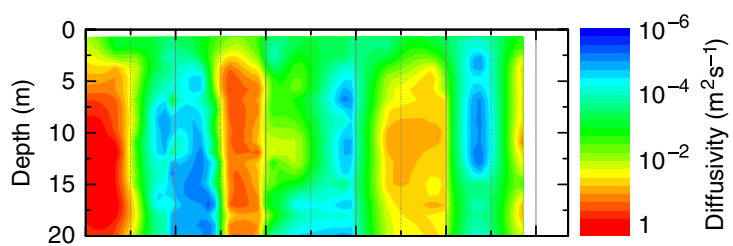

(c)

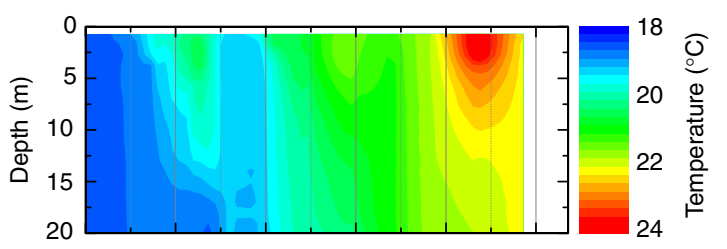

(d)

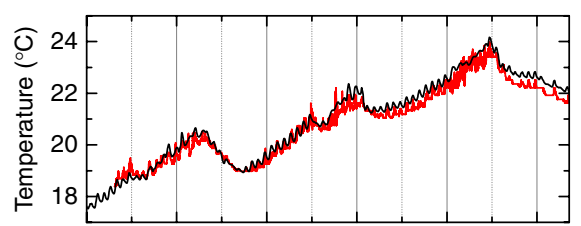

(e)
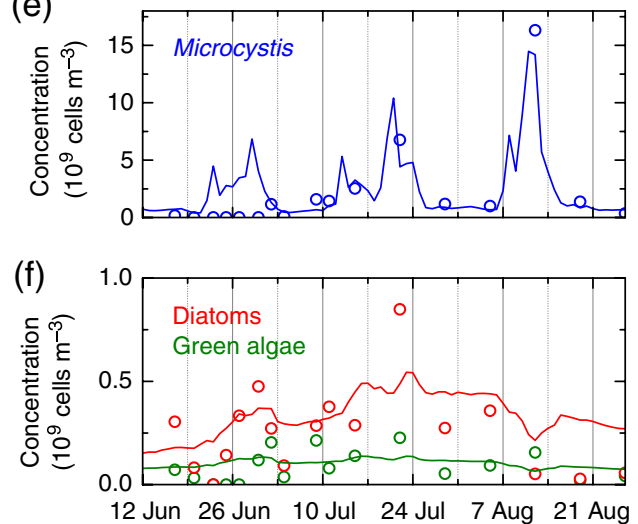

Fig. 3 Mixing experiment in Lake Nieuwe Meer during the summer heatwave of 2003. (a) Outline of the mixing experiment in Lake Nieuwe Meer. The line shows when artificial mixing was switched on and off. Dots show sampling dates for SCAMP profiles and phytoplankton. (b) Contour plot of vertical turbulent diffusivity, measured with the SCAMP profiler in downward mode (hence, the first $0.5 \mathrm{~m}$ could not be measured). (c) Contour plot of temperature, measured with the SCAMP profiler. (d) Temperature at $4 \mathrm{~m}$ depth, observed with temperature loggers (red line) and predicted by model simulations (black line). (e) Observed and simulated population densities of Microcystis near the water surface $(0-1 \mathrm{~m})$. (f) Observed and simulated population densities of diatoms (red) and green algae (green) near the water surface $(0-1 \mathrm{~m})$. Solid lines in (e) and (f) are model predictions, symbols represent measured data.

surface blooms. More precisely, when the spikes hit the smooth dashed lines in Fig. 4, the entire Microcystis population is concentrated in the upper meter of the water column. Comparison with the turbulent diffusivity patterns (Fig. 4, second row) shows that surface blooms were predicted during periods with very low turbulent mixing. Suitable conditions for the development of surface blooms occurred only a few days per month, even during the summer heatwave of 2003. In contrast to the frequent ups and downs of the surface concentration, the depth-integrated population of Microcystis (dashed line) showed smooth seasonal changes. Hence, the model predicted that Microcystis populations were characterized by slow seasonal dynamics, but with frequent redistributions of the population over depth due to changes in turbulent mixing. The model further predicted that the peaks of the diatoms and green algae occurred during periods with strong vertical mixing. Interestingly, the timing of the surface blooms of Microcystis often coincided with little dips in the surface concentrations of the diatoms and green algae (compare the two lower panels in Fig. 4a).

\section{Impact of different meteorological factors}

The summer heatwave of 2003 was characterized not only by high temperatures but also by reduced wind speed and little cloudiness (Fig. 1). The simulations in Fig. 4 do not say which of these different meteorological factors are the key determinants of the explosion of the Microcystis population during the summer heatwave of 2003. Therefore, we ran a second set of model simulations to unravel how the factors temperature, wind speed, and cloudiness have contributed to the population development of Microcystis in 2003. For this purpose, we first simulated the full model under the assumption that 2003 would have been an average summer. That is, we transformed the meteorological data, by shifting the hourly meteorological time series of 2003 by a constant value in such a way that the summer-averaged meteorological conditions would fall exactly on the trendlines for the year 2003 (Fig. 1). We shall call this the trend year. The phytoplankton development predicted for the trend year was quite similar to the phytoplankton development simulated for the cold summer of 1956 and the average summer of 1991, with maximum surface concentrations of $\sim 0.2 \times 10^{12}$ cells m ${ }^{-3}$ (Fig. 5a; compare with Fig. 4a and $b$ ).

Next, we investigated the sole effect of reduced cloudiness, by forcing the model with the cloudiness actually observed in 2003 while maintaining the wind speed and air temperature on the trend line. This showed that a decrease in cloudiness, and hence an increase in surface irradiance, led to a higher summer abundance of Microcystis (Fig. 5b). In a similar way, we investigated the impact of the reduced wind speed and 
(a)
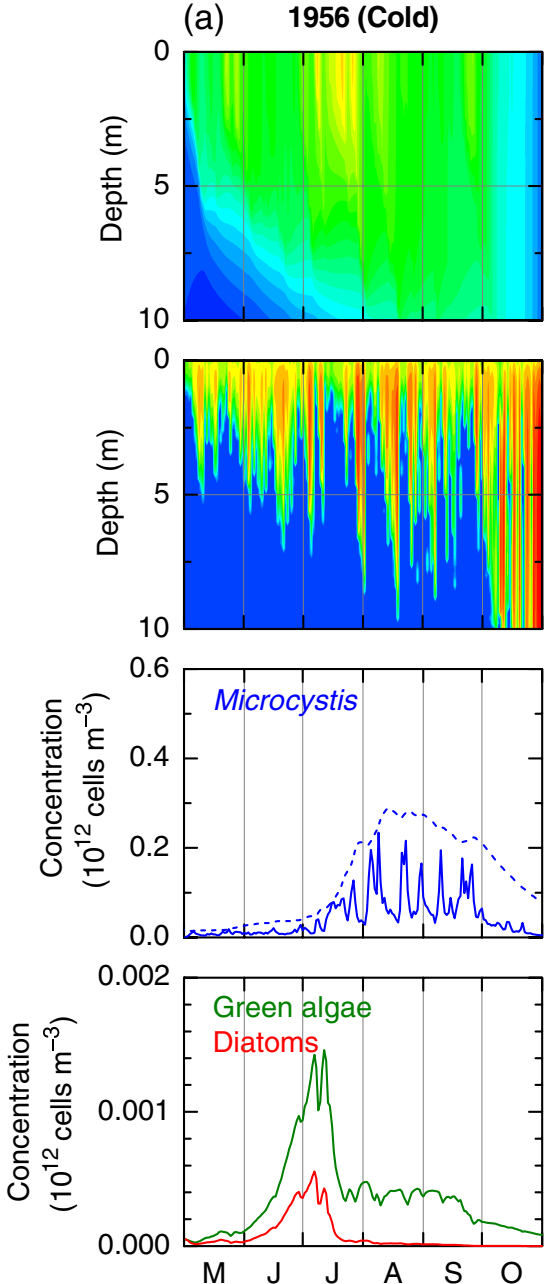

(b) 1991 (Normal)
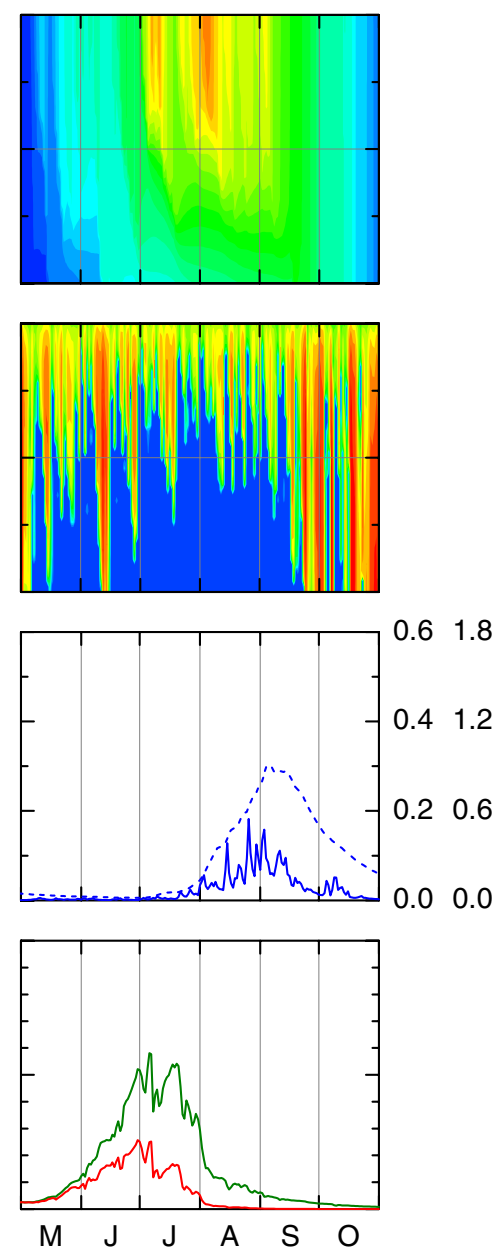

(c) 2003 (Hot)
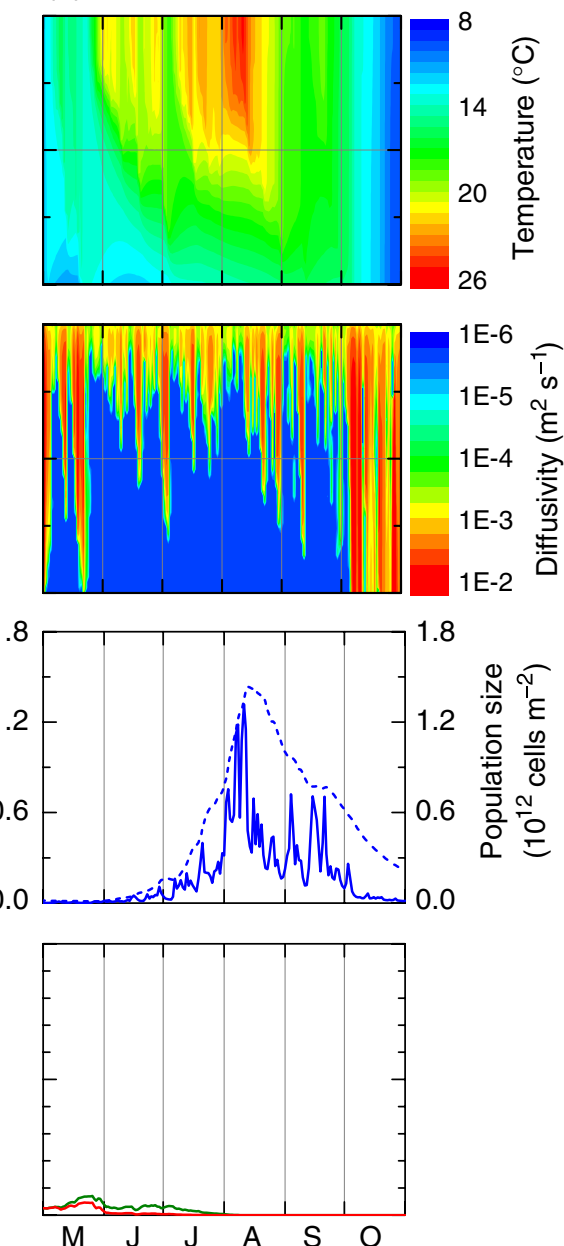

Fig. 4 Model simulation of hydrodynamics and phytoplankton dynamics during three contrasting summers. (a) The cold summer of 1956, (b) the average summer of 1991, and, (c) the hot summer of 2003. Top panels show the temperature contour plots. The second row shows contour plots of the turbulent diffusivities. The third row shows the surface concentrations of Microcystis (solid lines, in cells $\mathrm{m}^{-3}$ ) and the depth-integrated population size of Microcystis (dashed lines, in cells $\mathrm{m}^{-2}$ ). The fourth row shows the surface concentrations of diatoms (red lines) and green algae (green lines). Note the difference in scale between the Microcystis concentrations (third row) and the concentrations of diatoms and green algae (fourth row).

increased air temperatures of 2003, respectively. Reduced wind speed also led to a higher summer abundance of Microcystis (Fig. 5c; compare with Fig. 5a). Similarly, increased air temperatures clearly yielded a higher summer abundance of Microcystis (Fig. 5d; compare Fig. 5a). Comparison of Fig. 5b-d shows that the summer abundance of Microcystis responded more strongly to the increased air temperatures of 2003 than to the reduced cloudiness and reduced wind speed of 2003.

Model simulations using the complete meteorology of 2003 revealed that the combination of reduced cloudiness, reduced wind speed, and increased air temperatures led to a considerably higher summer abundance of Microcystis than any of these factors in isolation (Fig. 5e; compare with Fig. 5b-d). Thus, according to the model simulations, the explosion of Microcystis during the exceptional summer heatwave of 2003 should not be attributed to a single meteorological factor, like temperature, but resulted from the combined effects of low cloudiness, low wind speeds, and high air temperatures.

Low wind speeds and high air temperature do not affect phytoplankton growth directly, but only indirectly, through changes in water temperature and turbulent mixing. Hence, what is the relative contribution of these different pathways to the development of Microcystis blooms during summer heatwaves? We addressed this question by further comparison of the model simulations using the actual meteorology of 2003 with model 
(a)

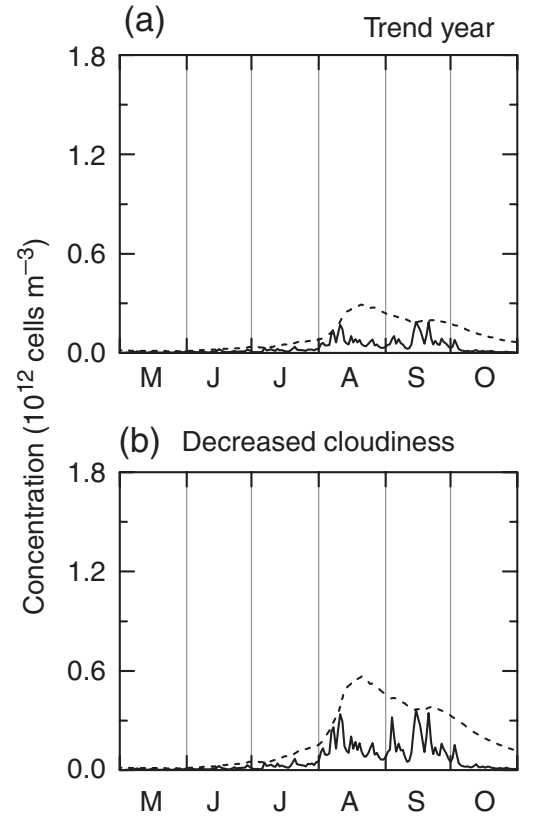

Meteorology 2003:

Decreased cloudiness Decreased wind speed Increased air temperature

(c) Decreased wind speed

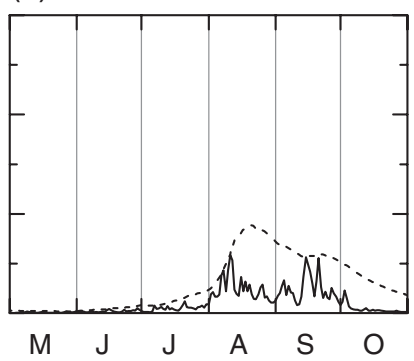

(e)

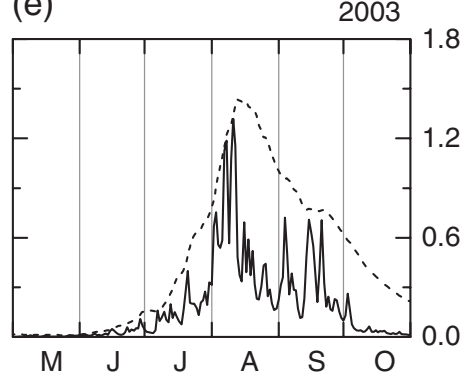

(d) Increased air temperature

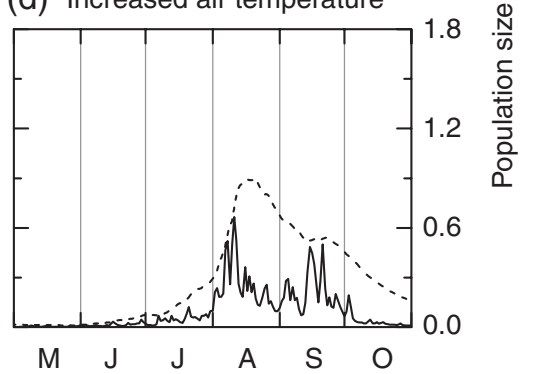

Fig. 5 Model prediction of the phytoplankton population dynamics, in response to changes in cloudiness, wind speed, and air temperature. (a) Model prediction assuming that cloudiness, wind speed, and air temperature match the values on the trendline predicted for 2003 (solid lines in Fig. 1). (b-d) Model predictions when one of these meteorological factors is represented by the actual values measured during the summer heatwave of 2003, while the other two factors match the long-term trend values. (b) Model prediction when cloudiness is reduced to the actual values measured during the summer heatwave of 2003. (c) Model prediction when wind speed is reduced to the actual values measured during the summer heatwave of 2003. (d) Model prediction when air temperature is increased to the actual values measured during the summer heatwave of 2003. (e) Model prediction when cloudiness, wind speed, and air temperature all take the actual values measured during the summer heatwave of 2003. Solid lines show the surface concentrations of Microcystis (in cells $\mathrm{m}^{-3}$ ), while dashed lines show the depth-integrated population size of Microcystis (in cells $\mathrm{m}^{-2}$ ).

simulations using the meteorological conditions calculated for the trend year. During the summer heatwave of 2003 , the air temperature was $1.8^{\circ} \mathrm{C}(=11 \%)$ higher than expected by the trend line (Figs 1a and 6). Cloudiness and wind speed in 2003 were $19 \%$ and $10 \%$ lower than expected by the trend line (Figs $1 \mathrm{~b}, \mathrm{c}$ and 6 ). According to the model simulations, this resulted in a $10 \%$ higher water temperature and a $9 \%$ lower magnitude of turbulent diffusivity during the summer heatwave of 2003 (Fig. 6). The high water temperature and low turbulent diffusivity, in turn, suppressed the population abundances of diatoms and green algae by 70 $87 \%$ when compared with the trend year. These strong negative effects exceeded the positive effect of reduced cloudiness on diatoms and green algae. The increase in water temperature during the summer heatwave, by $1.9^{\circ} \mathrm{C}$, had a very large positive effect on the Microcystis population (an increase of 385\%; Fig. 6), while the low turbulent diffusivity had a smaller positive effect. Reduced cloudiness had only a minor direct effect on the Microcystis population. In total, the model simulations predicted that the 2003 conditions increased the Microcystis population by $508 \%$, which exceeded the additive contributions of the different pathways. This points at synergistic effects of high water temperature and low turbulent diffusivity on the development of Microcystis blooms during summer heatwaves.

\section{Discussion}

Originally, this study did not intend to investigate the impact of climate change on harmful cyanobacteria. We set out to study how intermittent artificial mixing of Lake Nieuwe Meer would suppress surface blooms of Microcystis. However, owing to the extreme summer of 2003, we obtained a study on the response of Microcystis to a major summer heatwave. The combination of the lake experiment with a summer heatwave allowed us to disentangle the effect of mixing processes and weather conditions on the population development of this harmful cyanobacterium. Both the model predictions and experimental results show that, during the summer heatwave of 2003, Microcystis rapidly increased as soon as artificial mixing was switched off (Fig. 3).

We have aimed to develop a model that can make realistic predictions on the development of harmful 


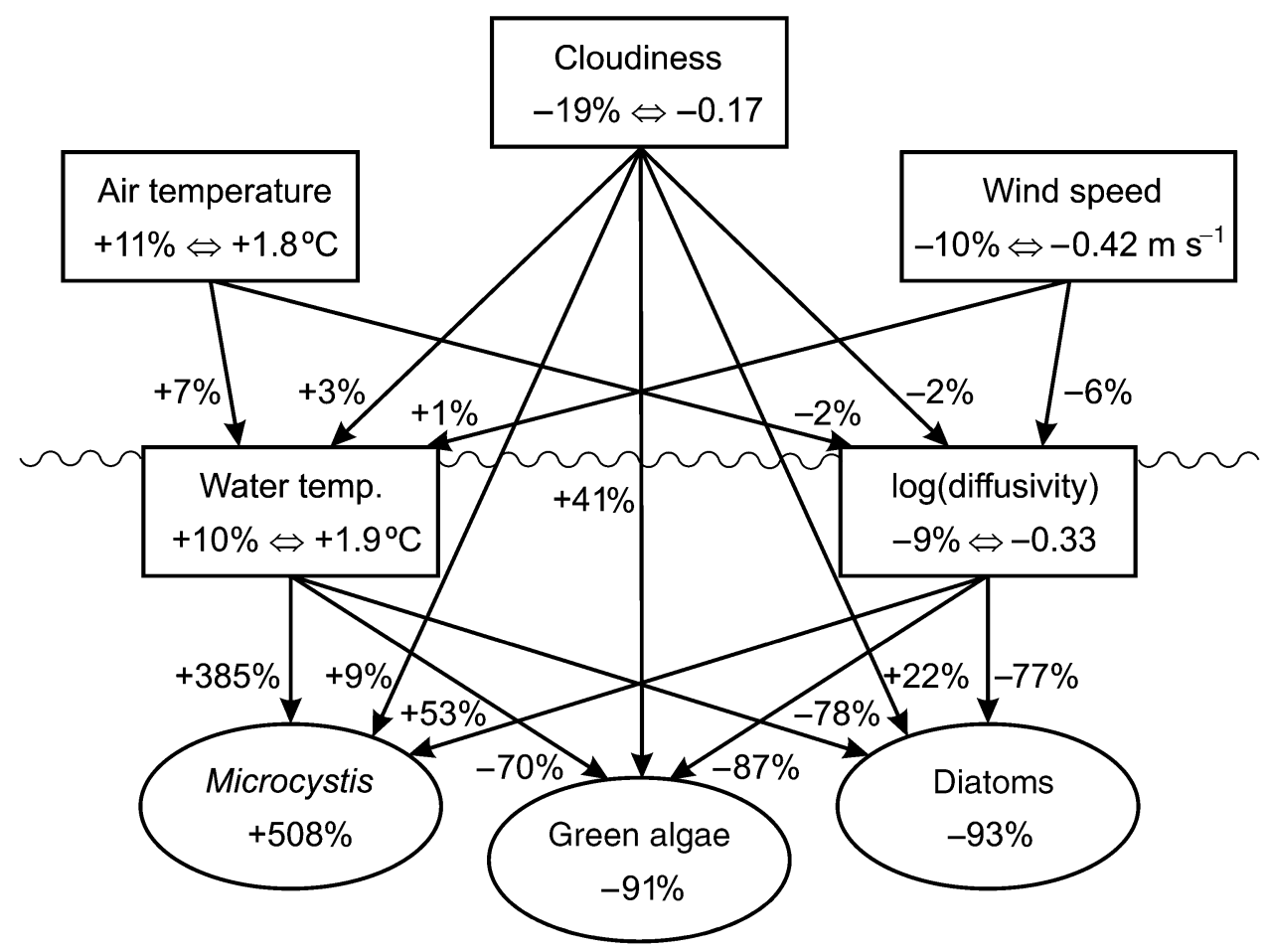

Fig. 6 Schematic summary of the effects of summer heatwaves on phytoplankton biomass. The upper level represents the meteorological variables (air temperature, cloudiness, and wind speed). These meteorological variables affect the water temperature and turbulent diffusivity of aquatic ecosystems. Water temperature, cloudiness ('light'), and turbulent diffusivity drive the population dynamics of the phytoplankton species. For each variable, the numbers inside the boxes give the relative and absolute differences between the summer heatwave of 2003 and an average summer (where an average summer is defined by meteorological conditions that fall on the trendlines in Fig. 1). Percentages along the arrows show the relative differences between the summer heatwave of 2003 and an average summer, caused by the pathway represented by that arrow. For instance, all else being equal, high water temperatures during the summer heatwave of 2003 were responsible for a 385\% increase of the Microcystis population compared with an average summer. In total, the Microcystis concentration was 508\% higher during the summer heatwave of 2003 than during an average summer. Note that the percentages of different pathways do not add up, because of interactive effects between different pathways. The values are based on model simulations; the turbulent diffusivity is evaluated on a log-10 scale.

cyanobacterial blooms in relation to climate change. Yet, all models are simplifications of reality, and our model is no exception to this rule. Several aspects of reality have been simplified or ignored. For instance, the physical part of the model ignored the spectral and angular distribution of the underwater light field (Kirk, 1994), as well as the transport of phytoplankton by horizontal processes (Verhagen, 1994). The biological part of the model neglected buoyancy regulation of Microcystis (Visser et al., 1997; Rabouille et al., 2005), and lumped more than 60 phytoplankton species identified in Lake Nieuwe Meer in only three functional groups. Despite these simplifications, we are confident that the model predictions are quite robust. The model structure is firmly based on well-tested physical models (Svensson, 1978; Jöhnk \& Umlauf, 2001; Peeters et al., 2007a) and plankton models (Huisman et al., 1999a, b, 2004; Passarge et al., 2006). Parameter estimates are based on detailed measurements of physical structure and phytoplankton physiological data (Reynolds, 1997; Huisman et al., 2004; Robson \& Hamilton, 2004; Butterwick et al., 2005), and the model predictions show good correspondence with the available data (Figs 2 and 3).

The model simulations illustrate that the development of Microcystis blooms is indeed very sensitive to the weather conditions in summer (Fig. 4). During cold summers, Microcystis cells may float upwards during periods of weak turbulent mixing and form surface blooms (Fig. 4a). The density of these surface blooms remains limited, however, because cold summers prevent the development of a large Microcystis population. In contrast, hot summers boost the growth of Microcystis populations through a combination of different mechanisms. First, Microcystis has a high temperature optimum compared with most diatoms and green algae, and an exceptionally large $Q_{10}$ value for growth compared with other phytoplankton species (Fig. 2b; 
see also Reynolds, 1997; Coles \& Jones, 2000; Butterwick et al., 2005). Hence, the maximum specific growth rate of Microcystis rises steeply with increasing temperatures. Second, high temperatures promote a strong stratification of the water column, thereby suppressing vertical turbulent mixing. In eutrophic waters, reduced vertical mixing shifts competition for light in favour of buoyant cyanobacteria like Microcystis, which float upwards to form dense surface blooms shading other phytoplankton species (Walsby et al., 1997; Huisman et al., 2004). Third, high temperatures reduce the viscosity of water. All else being equal, a lower viscosity yields higher flotation velocities of buoyant species and higher sinking velocities of sinking species, which also favours the dominance of buoyant cyanobacteria over sinking diatoms and green algae. According to our model simulations, the combination of these three mechanisms leads to dense surface blooms of Microcystis during summer heatwaves.

The development of dense surface blooms of buoyant cyanobacteria during summer heatwaves is confirmed by other studies. August 2003 yielded more reports on surface blooms of harmful cyanobacteria in lakes in the Netherlands than ever before (Kardinaal \& Visser, 2004). In the Oostvaardersplassen, one of the major bird sanctuaries in northwestern Europe, dense surface blooms of cyanobacteria were accompanied by mass mortalities of birds (especially ducks and geese). Several lakes were closed for recreation. In the southern hemisphere, an extremely dense bloom of Microcystis developed in the Swan River estuary, Australia, in the year 2000 (Atkins et al., 2001). This coincided with a very hot summer weather, with water temperatures approaching $30^{\circ} \mathrm{C}$. Model studies showed that these exceptionally high water temperatures, in combination with unusual hydrological conditions, favoured the bloom development of Microcystis in the Swan River estuary (Robson \& Hamilton, 2003, 2004). A recently published long-term study investigated the dominance of buoyant cyanobacteria (mainly Microcystis) in the Hudson River estuary, USA, in relation to physical and chemical parameters (Fernald et al., 2007). Cyanobacterial dominance and abundance were both strongly correlated with summer temperature, and over $80 \%$ of the among-year variance in cyanobacterial dominance could be explained by summer temperature in a linear model. Consistent with our findings, Fernald et al. (2007) attributed the observed cyanobacterial dominance during warm summers by the direct effect of temperature on cyanobacterial growth rates in combination with indirect effects through enhanced stratification and reduced vertical mixing.

These results add to previous studies, which have shown that a warmer climate predicted by climate change scenarios may shift the timing of the phytoplankton spring bloom (Edwards \& Richardson, 2004; Winder \& Schindler, 2004; Peeters et al., 2007b), and will lead to changes in phytoplankton species composition and phytoplankton diversity (Elliott et al., 2005; De Senerpont Domis et al., 2007). In accordance with recent findings of Elliott et al. (2006), we suggest that rising temperatures may have quite contrasting effects in oligotrophic and eutrophic waters. In oligotrophic waters, nutrient limitation prevents the development of dense phytoplankton blooms. Warming of surface layers will increase vertical stratification, which suppresses the upward flux of nutrients (Bopp et al., 2001; Sarmiento et al., 2004). As a consequence, rising temperatures may reduce the nutrient supply to the euphotic zone, and may thus reduce and even destabilize phytoplankton growth in oligotrophic waters (Schmittner, 2005; Behrenfeld et al., 2006; Huisman et al., 2006). In contrast, our results for Lake Nieuwe Meer are based on hypertrophic conditions, where nutrient limitation does not play a role. If nutrients are in excess, light energy is the major factor limiting phytoplankton growth. Buoyant cyanobacteria have a major advantage in competition for light, because they can increase their own access to light while casting shade upon their competitors (Walsby et al., 1997; Klausmeier \& Litchman, 2001; Huisman et al., 2004). Hence, the prediction that summer heatwaves promote dense surface blooms of buoyant cyanobacteria particularly applies to eutrophic and hypertrophic waters.

According to recent climate studies, the European summer heatwave of 2003 might be a prototype of future summers in the next 50-100 years (Beniston, 2004; Schär et al., 2004; Stott et al., 2004). These summer heatwaves are characterized by a very stable high-pressure system above northwestern Europe, generating high air temperatures, reduced wind speed, and reduced cloudiness compared with the long-term mean (Fig. 1). Our model simulations indicate that particularly high air temperatures, and also reduced wind speed and reduced cloudiness, each have the potential to promote the bloom development of Microcystis. The model points at the following climatic effects (Fig. 6):

(1) High air temperatures increase the water temperature of the surface-mixed layer. As discussed above, high water temperatures increase the growth rate of Microcystis, suppress vertical turbulent mixing, and reduce viscosity. Thus, high air temperatures strongly favour the development of Microcystis blooms.

(2) Reduced wind speed leads to a more stable stratification and a slightly shallower thermocline. This, 
in turn, also has a (small) positive effect on water surface temperatures. Reduced wind speeds are thus an advantage for buoyant Microcystis in terms of reduced vertical mixing and slight increase in water temperature.

(3) Reduced cloudiness, and hence sunnier conditions, slightly enhance the growth rate of buoyant cyanobacteria through an increased light availability. Furthermore, reduced cloudiness increases shortwave irradiance and decreases long-wave radiation entering the water column. In total, there is a net increase of the heat input, which leads to a slight increase in water temperature and reduced vertical mixing.

Although high air temperatures have the strongest effect on bloom development of Microcystis, the combination of high air temperatures with reduced wind speed and reduced cloudiness leads to an even higher summer abundance of Microcystis than any of these factors alone (Figs 5 and 6). This implies that studies that focus solely on changes in temperature, without taking into account wind speed and cloudiness, may seriously underestimate the impact of climate change on the bloom development of harmful cyanobacteria. This highlights the need for realistic future scenarios of wind speed and cloudiness in climate models. Whereas temperature scenarios are readily available from current climate models, there is still uncertainty in future scenarios for wind speed and cloudiness predicted by the current generation of climate models (McAvaney et al., 2001; Smits et al., 2005).

In conclusion, the theory and lake experiment presented in this study show that, in hypertrophic waters, summer heatwaves boost the population growth of Microcystis as soon as these buoyant cyanobacteria are released from vertical mixing. According to recent climate studies, the risk of European heatwaves as hot as 2003 will increase rapidly (Beniston, 2004; Schär et al., 2004; Stott et al., 2004). An increased threat of harmful cyanobacterial blooms thus seems a likely future scenario for eutrophic freshwater ecosystems.

\section{Acknowledgements}

We thank the anonymous referees for their thoughtful comments, and Floris de Jongh, Linda van den Hove, and Bart Schaub for field and lab assistance. We are most grateful to Water Board Rijnland for all help with the artificial mixing experiment. Meteorological data were kindly provided by the Royal Netherlands Meteorological Institute (KNMI). P. M. V., K. D. J. and J. H. were supported by the Earth and Life Sciences Foundation (ALW), which is subsidized by the Netherlands Organization for Scientific Research (NWO). B. S. acknowledges support from the Dutch BSIK-BRICKS project.

\section{References}

Atkins R, Rose T, Brown RS, Robb M (2001) The Microcystis cyanobacteria bloom in the Swan River-February 2000. Water Science and Technology, 43, 107-114.

Behrenfeld MJ, O'Malley RT, Siegel DA et al. (2006) Climatedriven trends in contemporary ocean productivity. Nature, 444, 752-755.

Beniston M (2004) The 2003 heat wave in Europe: a shape of things to come? An analysis based on Swiss climatological data and model simulations. Geophysical Research Letters, 31, L02202, doi: 10.1029/2003GL018857.

Bopp L, Monfray P, Aumont O et al. (2001) Potential impact of climate change on marine export production. Global Biogeochemical Cycles, 15, 81-99.

Butterwick C, Heaney SI, Talling JF (2005) Diversity in the influence of temperature on the growth rates of freshwater algae, and its ecological relevance. Freshwater Biology, 50, 291-300.

Carmichael WW (2001) Health effects of toxin-producing cyanobacteria: "The CyanoHABs". Human and Ecological Risk Assessment, 7, 1393-1407.

Chen CT, Millero FJ (1986) Precise thermodynamic properties for natural waters covering only the limnological range. Limnology and Oceanography, 31, 657-662.

Chen YW, Qin BQ, Teubner K, Dokulil MT (2003) Long-term dynamics of phytoplankton assemblages: Microcystis-domination in Lake Taihu, a large shallow lake in China. Journal of Plankton Research, 25, 445-453.

Chorus I, Bartram J (1999) Toxic Cyanobacteria in Water: A Guide to their Public Health Consequences, Monitoring and Management. Spon, London.

Codd GA, Bell SG, Kaya K, Ward CJ, Beattie KA, Metcalf JS (1999) Cyanobacterial toxins, exposure routes and human health. European Journal of Phycology, 34, 405-415.

Coles JF, Jones RC (2000) Effect of temperature on photosynthesis-light response and growth of four phytoplankton species isolated from a tidal freshwater river. Journal of Phycology, 36, 7-16.

De Senerpont Domis LN, Mooij WM, Huisman J (2007) Climateinduced shifts in an experimental phytoplankton community: a mechanistic approach. Hydrobiologia, 584, 403-413.

DeMott WR (1999) Foraging strategies and growth inhibition in five daphnids feeding on mixtures of a toxic cyanobacterium and a green alga. Freshwater Biology, 42, 263-274.

Edwards M, Richardson AJ (2004) Impact of climate change on marine pelagic phenology and trophic mismatch. Nature, 430, 881-884.

Elliott JA, Jones ID, Thackeray SJ (2006) Testing the sensitivity of phytoplankton communities to changes in water temperature and nutrient load, in a temperate lake. Hydrobiologia, 559, 401-411.

Elliott JA, Thackeray SJ, Huntingford C, Jones RG (2005) Combining a regional climate model with a phytoplankton community model to predict future changes in phytoplankton in lakes. Freshwater Biology, 50, 1404-1411.

Fernald SH, Caraco NF, Cole JJ (2007) Changes in cyanobacterial dominance following the invasion of the zebra mussel Dreissena polymorpha: long-term results from the Hudson River Estuary. Estuaries and Coasts, 30, 163-170. 
Ghadouani A, Pinel-Alloul B, Prepas EE (2003) Effects of experimentally induced cyanobacterial blooms on crustacean zooplankton communities. Freshwater Biology, 48, 363-381.

Henderson-Sellers B (1984) Engineering Limnology. Pitman, London.

Huisman J, Jonker RR, Zonneveld C, Weissing FJ (1999a) Competition for light between phytoplankton species: experimental tests of mechanistic theory. Ecology, 80, 211-222.

Huisman J, Matthijs HCP, Visser PM (eds) (2005) Harmful Cyanobacteria. Springer, Berlin, Germany.

Huisman J, van Oostveen P, Weissing FJ (1999b) Critical depth and critical turbulence: two different mechanisms for the development of phytoplankton blooms. Limnology and Oceanography, 44, 1781-1787.

Huisman J, Pham Thi NN, Karl DM, Sommeijer B (2006) Reduced mixing generates oscillations and chaos in the oceanic deep chlorophyll maximum. Nature, 439, 322-325.

Huisman J, Sharples J, Stroom J, Visser PM, Kardinaal WEA, Verspagen JMH, Sommeijer B (2004) Changes in turbulent mixing shift competition for light between phytoplankton species. Ecology, 85, 2960-2970.

Huisman J, Sommeijer BP (2002) Population dynamics of sinking phytoplankton in light-limited environments: simulation techniques and critical parameters. Journal of Sea Research, 48, 83-96.

Hutter K (1993) Waves and oscillations in the ocean and in lakes. In: Continuum Mechanics in Environmental Sciences and Geophysics (ed Hutter K), pp. 79-240. Springer, Wien.

Hutter K, Jöhnk KD (2004) Continuum Methods of Physical Modeling - Continuum Mechanics, Dimensional Analysis, Turbulence. Springer, Berlin, Germany.

Ibelings BW, Vonk M, Los HFJ, van der Molen DT, Mooij WM (2003) Fuzzy modeling of cyanobacterial surface waterblooms: validation with NOAA-AVHRR satellite images. Ecological Applications, 13, 1456-1472.

Imberger J, Ivey GN (1991) On the nature of turbulence in a stratified fluid. II: application to lakes. Journal of Physical Oceanography, 21, 659-680.

Imboden DM, Wüest A (1995) Mixing mechanisms in lakes. In: Physics and Chemistry of Lakes, 2nd edn (eds Lerman A, Imboden DM, Gat JR), pp. 83-138. Springer, Berlin, Germany.

Jöhnk KD (2005) Heat balance of open water bodies. In: Water Encyclopedia, Vol. 3: Surface and Agricultural Water (eds Lehr JH, Keeley J), pp. 190-193. John Wiley \& Sons, Hoboken, NJ.

Jöhnk KD, Umlauf L (2001) Modelling the metalimnetic oxygen minimum in a medium sized alpine lake. Ecological Modelling, 136, 67-80.

Jones WP, Launder BE (1972) The prediction of laminarization with a two-equation model of turbulence. International Journal of Heat and Mass Transfer, 15, 301-314.

Kardinaal WEA, Visser PM (2004) Cyanotoxines Drijven tot Overlast: Inventarisatie van Microcystine Concentraties 2000-2004 in Nederlandse Oppervlakte Wateren. Report for the National Institute for Inland Water Management and Wastewater Treatment, the Netherlands, 23 pp.

Kirk JTO (1994) Light and Photosynthesis in Aquatic Ecosystems, 2nd edn. Cambridge University Press, Cambridge, UK.
Klausmeier CA, Litchman E (2001) Algal games: the vertical distribution of phytoplankton in poorly mixed water columns. Limnology and Oceanography, 46, 1998-2007.

Kocsis O, Prandke H, Stips A, Simon A, Wüest A (1999) Comparison of dissipation of turbulent kinetic energy determined from shear and temperature microstructure. Journal of Marine Systems, 21, 67-84.

Launder BE, Spalding DB (1974) The numerical computation of turbulent flow. Computer Methods in Applied Mechanics and Engineering, 3, 269-289.

Levinson DH, Waple AM (2004) State of climate in 2003. Bulletin of the American Meteorological Society, 85, S1-S72.

Luterbacher J, Dietrich D, Xoplaki E, Grosjean M, Wanner H (2004) European seasonal and annual temperature variability, trends, and extremes since 1500. Science, 303, 1499-1503.

McAvaney BJ, Covey C, Joussaume S et al. (2001) Model evaluation. In: Climate Change 2001: The Scientific Basis. Contribution of Working Group I to the Third Assessment Report of the Intergovernmental Panel on Climate Change (eds Houghton JT, Ding Y, Griggs DJ, Noguer M, van der Linden PJ, Dai X, Maskell K, Johnson CA), pp. 471-523. Cambridge University Press, Cambridge.

Mohammadi B, Pironneau O (1994) Analysis of the K-Epsilon Turbulence Model. Wiley \& Sons, Chichester.

Mooij WM, Hülsmann S, De Senerpont Domis LN et al. (2005) The impact of climate change on lakes in the Netherlands: a review. Aquatic Ecology, 39, 381-400.

Passarge J, Hol S, Escher M, Huisman J (2006) Competition for nutrients and light: stable coexistence, alternative stable states, or competitive exclusion? Ecological Monographs, 76, 57-72.

Peeters F, Straile D, Lorke A, Livingstone DM (2007b) Earlier onset of the spring phytoplankton bloom in lakes of the temperate zone in a warmer climate. Global Change Biology, 13, 1898-1909.

Peeters F, Straile D, Lorke A, Ollinger D (2007a) Turbulent mixing and phytoplankton spring bloom development in a deep lake. Limnology and Oceanography, 52, 286-298.

Pham Thi NN, Huisman J, Sommeijer B (2005) Simulation of 3D phytoplankton dynamics: competition in light-limited environments. Journal of Computational and Applied Mathematics, 174, 57-77.

Rabouille S, Salençon MJ, Thébault JM (2005) Functional analysis of Microcystis vertical migration: a dynamic model as a prospecting tool, I - Processes analysis. Ecological Modelling, 188, 386-403.

Raven JA, Geider RJ (1988) Temperature and algal growth. New Phytologist, 110, 441-461.

Reynolds CS (1997) Vegetation Processes in the Pelagic: A Model for Ecosystem Theory. Ecology Institute, Oldendorf.

Reynolds CS (2006) Ecology of Phytoplankton. Cambridge University Press, Cambridge.

Reynolds CS, Jaworski GMH, Cmiech HA, Leedale GF (1981) On the annual cycle of the blue-green alga Microcystis aeruginosa Kütz. emend. Elenkin. Philosophical Transactions of the Royal Society London, Series B, 293, 419-477.

Robarts RD, Zohary T (1987) Temperature effects on photosynthetic capacity, respiration, and growth rates of bloom-forming cyanobacteria. New Zealand Journal of Marine and Freshwater Research, 21, 391-399. 
Robson BJ, Hamilton DP (2003) Summer flow event induces a cyanobacterial bloom in a seasonal Western Australian estuary. Marine and Freshwater Research, 54, 139-151.

Robson BJ, Hamilton DP (2004) Three-dimensional modeling of a Microcystis bloom event in the Swan River estuary, Western Australia. Ecological Modelling, 174, 203-222.

Rodi W (1993) Turbulence Models and their Application in Hydraulics - a State of the Art Review, 3rd edn. Balkema, Rotterdam.

Rohrlack T, Dittmann E, Henning M, Börner T, Kohl JG (1999) Role of microcystins in poisoning and food ingestion inhibition of Daphnia galeata caused by the cyanobacterium Microcystis aeruginosa. Applied and Environmental Microbiology, 65, 737-739.

Ryan MG (1991) Effects of climate change on plant respiration. Ecological Applications, 1, 157-167.

Sarmiento JL, Slater R, Barber R et al. (2004) Response of ocean ecosystems to climate warming. Global Biogeochemical Cycles, 18, GB3003, doi: 10.1029/2003GB002134.

Sas H (1989) Lake Restoration by Reduction of Nutrient Loading: Expectations, Experience, Extrapolations. Academia Verlag Richarz, St Augustin.

Schär C, Vidale PL, Luthi D, Frei C, Häberli C, Liniger MA, Appenzeller C (2004) The role of increasing temperature variability in European summer heatwaves. Nature, 427, 332336.

Schmittner A (2005) Decline of the marine ecosystem caused by a reduction in the Atlantic overturning circulation. Nature, 434, 628-633.

Sharples J, Moore CM, Abraham ER (2001) Internal tide dissipation, mixing, and vertical nitrate flux at the shelf edge of NE New Zealand. Journal of Geophysical Research, 106, 1406914081.

Smayda TJ (1970) The suspension and sinking of phytoplankton in the sea. Oceanography and Marine Biology Annual Review, 8, 353-414.

Smits A, Klein Tank AMG, Können GP (2005) Trends in storminess over the Netherlands, 1962-2002. International Journal of Climatology, 25, 1331-1344.
Stevens C, Smith M, Ross A (1999) SCAMP: measuring turbulence in estuaries, lakes, and coastal waters. NIWA - Water and Atmosphere, 7, 20-21.

Stott PA, Stone DA, Allen MR (2004) Human contribution to the European heatwave of 2003. Nature, 432, 610-614.

Svensson U (1978) A Mathematical Model of the Seasonal Thermocline. PhD Thesis, University of Lund, 187 pp.

Verhagen JHG (1994) Modeling phytoplankton patchiness under the influence of wind-driven currents in lakes. Limnology and Oceanography, 39, 1551-1565.

Verspagen JMH, Passarge J, Jöhnk KD et al. (2006) Water management strategies against toxic Microcystis blooms in the Dutch delta. Ecological Applications, 16, 313-327.

Visser PM, Ibelings BW, Van der Veer B, Koedood J, Mur LR (1996a) Artificial mixing prevents nuisance blooms of the cyanobacterium Microcystis in Lake Nieuwe Meer, The Netherlands. Freshwater Biology, 36, 435-450.

Visser PM, Massaut L, Huisman J, Mur LR (1996b) Sedimentation losses of Scenedesmus in relation to mixing depth. Archiv für Hydrobiologie, 136, 289-308.

Visser PM, Passarge J, Mur LR (1997) Modelling vertical migration of the cyanobacterium Microcystis. Hydrobiologia, 349, 99-109.

Walsby AE (1994) Gas vesicles. Microbiological Reviews, 58, 94-144.

Walsby AE, Hayes PK, Boje R, Stal LJ (1997) The selective advantage of buoyancy provided by gas vesicles for planktonic cyanobacteria in the Baltic Sea. New Phytologist, 136, 407-417.

Wetzel RG (2001) Limnology, 3rd edn. Academic Press, San Diego. Wilcox DC (1993) Turbulence Modeling for CFD. DCW Industries, La Cañada.

Winder M, Schindler DE (2004) Climate change uncouples trophic interactions in an aquatic ecosystem. Ecology, 85, 2100-2106.

Zohary T, Pais-Madeira AM, Robarts R, Hambright KD (1996) Interannual phytoplankton dynamics of a hypertrophic African lake. Archiv für Hydrobiologie, 136, 105-126.

Zohary T, Robarts RD (1990) Hyperscums and the population dynamics of Microcystis aeruginosa. Journal of Plankton Research, 12, 423-432. 